\title{
Contribuições da sociolinguística ao ensino do português em comunidades bilíngues do norte do Uruguai
}

\author{
Ana Maria Carvalho*
}

Resumo: Este artigo tem como objetivo discutir alguns fatores sociolinguísticos relevantes ao ensino de português nas comunidades bilíngues em espanhol e português no norte do Uruguai. Nele, destaco duas das características do repertório linguístico dessas comunidades: o bilinguismo e suas consequências nas variedades em contato, como a alternância de códigos e a congruência gramatical; e os padrões de variação interna, tanto do português como do espanhol fronteiriço. Após contribuir com uma descrição do repertório bilíngue e multidialetal nessas comunidades e descartar o mito de monolinguismo e monoestilismo, discuto algumas premissas que devem ser consideradas pelo ensino do português nessas comunidades, explorando algumas sugestóes pedagógicas oferecidas no campo de ensino de língua materna e de língua de herança. $\mathrm{O}$ objetivo final é contribuir ao desenvolvimento de uma pedagogia sensível às diferenças sociolinguísticas e culturais dos alunos residentes na fronteira.

Palavras-chave: português uruguaio; espanhol fronteiriço; bilinguismo; variação; sociolinguística.

\section{Sociolinguistic contributions to the teaching of Portuguese in the bilingual communities of northern Uruguay}

Abstract: This article is aimed at discussing sociolinguistic factors that are relevant to the teaching of Portuguese in the Spanish-Portuguese bilingual communities of northern Uruguay. It explores two of the main characteristics of these communities' linguistic repertoire: bilingualism and its consequences on the contact varieties, such as code-switching and grammatical convergence and patterns of internal linguistic variation, both in Portuguese and in Spanish. After contributing with a description of these communities' bilingual and multidialectal repertoires and arguing against the idea of monolingual and monostylistic speakers, the text brings a discussion on some premises that should be considered in the teaching of Portuguese in these communities, borrowing some pedagogical suggestions from the fields of first- and heritage-language teaching. Its final objective is to contribute to the development of a set of pedagogical principles that take students' sociolinguistic and cultural differences into account.

Key words: Uruguayan Portuguese; border Spanish; bilingualism; variation; sociolinguistics.

* Associate Professor, Department of Spanish and Portuguese, University of Arizona. Estados Unidos da América. anac@u.arizona.edu 
[...] a tarefa da sociolingüística educacional não se esgota na descrição da variação e divulgação dos resultados obtidos [...]. O que é preciso, de fato, é contribuir para o desenvolvimento de uma pedagogia sensivel às diferenças sociolingüísticas e culturais dos alunos e isto requer uma mudança de posturas da escola e da sociedade em geral. Para tal mudança de postura, todavia, a descrição das regras variáveis é uma etapa preliminar importante.

(Bortoni-Ricardo, 2005, p. 130)

\section{Introdução}

Algumas comunidades no norte do Uruguai apresentam casos de bilinguismo social, ou seja, contextos que não envolvem necessariamente nem aquisição nem perda de língua entre falantes que têm por hábito usar português e espanhol alternadamente. Devido à justaposição de, por um lado, políticas linguísticas que difundiram e difundem o ensino e o uso do espanhol e, por outro, preservação do português uruguaio como língua de identidade regional, transmitida através de gerações, atualmente se encontram comunidades bilíngues nos departamentos de Rivera, Artigas, Cerro Largo e Chuí. Apesar de uma forte semelhança estrutural com os dialetos populares do sul do Brasil, o português uruguaio é altamente estigmatizado nessas comunidades onde o espanhol é a variedade de prestígio.

Este artigo tem como objetivo discutir alguns fatores sociolinguísticos relevantes ao ensino de português nessas comunidades, destacando as características do repertório linguístico local, sobretudo no que concerne a fenômenos de contato, como a alternância de códigos e a congruência gramatical, e à variação interna, tanto do português como do espanhol fronteiriço. Após oferecer uma descrição do repertório bilíngue e multidialetal de Rivera e Artigas, cidades onde os dados nos quais me baseio foram coletados, traçarei algumas premissas que, ao meu entender, devem ser consideradas no ensino de português nessas comunidades, esperando contribuir, como nos urge Bortoni-Ricardo na epígrafe, ao desenvolvimento de uma pedagogia sensível às diferenças sociolinguísticas e culturais dos alunos. De fundamental importância a essa primeira etapa, ou seja, à descrição do repertório linguístico local, é a investigação dos princípios sociolinguísticos que regem o comportamento linguístico dessas comunidades, entendimento esse que deve servir como subsídio para a elaboração de estratégias pedagógicas e de material didático adequado.

Portanto, para que seja possível dar a devida atenção à influência da diversidade linguística no processo educacional, é basilar que a diversidade linguística 
presente nas comunidades de fala bilíngue no norte do Uruguai seja explorada de diversos ângulos, tanto a variação interna de cada idioma em contato, ou seja, o multidialetalismo, como os fatores sociais que condicionam a escolha de idiomas, ou seja, o bilinguismo. Em cidades fronteiriças como Rivera e Artigas, as crianças são socializadas em ambos os idiomas. Crescem ouvindo português rural dos familiares, comerciantes de bairro e vizinhos. $\mathrm{Na}$ escola e nos espaços públicos, usam o espanhol local, enquanto ouvem o espanhol montevideano dos meios de comunicação e dos visitantes capitalinos. Diariamente são expostos ao português brasileiro urbano através dos meios de comunicação, das relaçōes com brasileiros e das propagandas em alto-falantes que anunciam produtos vendidos do outro lado da fronteira. Essa diversidade linguística, somente capturada através de métodos etnográficos e longos períodos de observação sistemática, caracteriza a socialização dos fronteiriços em centros urbanos.

É devido à exposição constante aos dialetos monolíngues circundantes que frequentemente os bilíngues acreditam que falam uma variedade linguística inferior ao português brasileiro e ao espanhol do sul do país. Essa insegurança linguística, comum em sociedades bilíngues, leva os falantes de português uruguaio a menosprezar esse idioma, conferindo-lhe status de uma variedade híbrida, um "portunhol". Tal visão monolítica do repertório linguístico dos falantes de português uruguaio responde a principalmente três ideologias linguísticas: a noções artificiais de purismo, ao status do português como língua minoritária e ao fato de este ser falado fora das fronteiras nacionais, ideologias discutidas em detalhes em Carvalho (2008). No presente trabalho, exploro a ecologia linguística nessas comunidades, a fim de desvendar um repertório extremamente diversificado, que inclui não somente dois sistemas linguísticos, português e espanhol, mas também padrões sistemáticos de variação inter e intralinguística. Em vez de aleatória e assistemática, veremos que tanto a escolha de línguas como a variação interna são condicionadas por fatores sociais e interacionais. Proponho, finalmente, que a ideia de diversidade linguística substitua a ideia de um dialeto híbrido e monoestilístico e passe a ser considerada como ferramenta fundamental no âmbito educacional.

\section{Bilinguismo}

Ainda que não haja dados estatísticos exatos sobre o número de bilíngues nas comunidades fronteiriças, é consensual a presença de um bilinguismo social nos centros urbanos e suburbanos, onde a maioria da população usa ambos os idiomas na vida diária (Behares, 1984; Carvalho, 2006c; Elizaincín, 1978, 1992, 2008). Ainda assim, em comunidades rurais e isoladas é possível encontrar bilíngues somente passivos, falantes de português que compreendem o 
espanhol, mas não são fluentes. Nas periferias das zonas urbanas, entre os membros dos grupos socioeconômicos baixos, os mais velhos, e aqueles com vínculos rurais, encontram-se bilíngues dominantes em português com vários níveis de competência em espanhol. Waltermire (2006) estuda a influência do português nos padrões fonológicos do espanhol em Rivera através de uma análise variacional e detecta que a pronúncia oclusiva de /d/ intervocálico em espanhol, oriunda do substrato português, é preferida por homens, mais velhos e membros da classe social baixa, exatamente por serem esses os grupos dominantes em português. $\mathrm{O}$ espanhol, por sua vez, é favorecido pelas classes mais altas, pelas mulheres e pelos mais jovens (Carvalho, 2007), e é possível encontrar membros desses grupos que tenham competência passiva de português, mas preferem não usá-lo, sobretudo aqueles que foram socializados no centro da cidade e em colégios particulares, meios onde prevalecem os valores culturais nacionais e o uso da língua espanhola.

Essas diferenças em níveis de bilinguismo refletem o contínuo de proficiência linguística proposto por Silva-Corvalán (1996) para descrever as comunidades falantes de espanhol e inglês em Los Angeles, Califórnia. No entanto, diferentemente das comunidades de imigrantes, onde se espera uma rápida substituição da língua minoritária pela língua majoritária (geralmente em três gerações), nas comunidades fronteiriças o bilinguismo é mais estável e tem resistido à imposição do espanhol desde os fins do século XIX, mantendo-se até hoje graças ao seu forte valor identitário. Uma anedota retirada das minhas observaçôes em 1995 ilustra a importância do português como símbolo da cultura local. Na época, entrevistei a família de J., um líder comunitário do bairro operário Manduvi, habitado pela classe trabalhadora e localizado na periferia de Rivera, onde se ouve quase exclusivamente o português. J. casou-se com uma moça de Montevidéu que havia se mudado com ele para Manduvi. Foi interessante ver como essa montevideana havia adquirido o português. Segundo ela, a sua exposição constante à nova língua e a importância de adquirila para que fosse aceita pela comunidade a fizeram bilíngue em pouco tempo.

Outra condição primordial que tem impedido a substituição do português pelo espanhol nessas comunidades é a dinâmica até certo ponto diglóssica. A distribuição funcional de idiomas recai na tendência de usar o espanhol nas esferas públicas, e o português nas interaçōes intragrupais e no âmbito doméstico. Essa dinâmica diglóssica já foi detectada nos trabalhos de Behares (1984), Elizaincín $(1975,1978,1992)$ e Carvalho (2007). No entanto, vale ressaltar que a diglossia aqui se concebe segundo o sentido amplo proposto por Fishman (1972), que permite certa justaposição de línguas em alguns contextos, como, por exemplo, o uso de espanhol também em ambientes domésticos. Em vez de uma separação rígida de idiomas, como sugeria Ferguson (1959), o acesso au- 
tomático a ambas as línguas em interações sociais possibilita que, em certos contextos, os falantes façam uso do espanhol e do português intercaladamente, com os mesmos interlocutores, nos mesmos domínios sociais, dentro da mesma conversa e, até mesmo, dentro da mesma frase, nos frequentes casos de alternância de código.

\section{2.a. Alternância de código}

A alternância de código tem sido estudada não como resultado de uma deficiência linguística, mas como uma habilidade, própria de indivíduos bilíngues, de explorar as possibilidades estilísticas em ambos os códigos (Poplack, 1980). Mais frequentes em registros informais e comunicações intragrupais (Poplack, 1993), a alternância pode servir a várias funções discursivas, como destacou Zentella (1997) na sua detalhada etnografia de um grupo bilíngue em Nova York. Nas comunidades bilíngues do Uruguai, vários casos de alternância entre o português e o espanhol também respondem a necessidades discursivas. A seguir traço uma breve análise de alguns desses casos.

M é uma senhora residente do bairro de Rivera Chico, em Rivera. Criada em português no interior do departamento, $\mathrm{M}$ ilustra-nos algumas das funçôes discursivas desempenhadas pela alternância entre o português e o espanhol. Vejamos a narrativa no exemplo 1 :

1. Un día vino la directora y los gurises estaban hablando en portugués, y la directora los corrigió y les dijo: "Doña M. puede hablar en portugués pero ustedes no". Y yo segui hablando no más en portugués. Me queda meió pa dizê as coisa, mas é claro se meus padre me criaron ansi! (M)

Neste exemplo, depois de narrar um acontecimento em espanhol, M passa para o português no momento que rompe a narrativa para avaliar seu comportamento, uma estratégia comumente usada pelos participantes bilíngues do estudo de Zentella (1997, p. 94-5).

M brinda-nos com outro exemplo que revela, além da importância do espanhol como língua exigida no âmbito público, a alternância de línguas na produção de uma pergunta retórica, mais uma vez, indicando rompimento de narrativa:

2. Ahora, si yo voy a una oficina, cualquier cosa, hablar con una persona de estudio, en castellano, con el doctor, que me duele acá, me duele, así asi, pero dai a poco ya empiezo en portugués, pero a veces me sale, fazê o quê? (M)

$\mathrm{M}$ explica ainda seus esforços para falar espanhol quando é necessário, no exemplo 3, em que narra suas estratégias de autocorreção, enfatizando a necessidade de usar espanhol em alguns contextos, graças à distribuição diglóssica dos idiomas: 
3. Por ejemplo, "eu vô" entonces yo ratifico, "yo voy" [enfático] para la persona que estoy hablando, "eu vô", recuerdo que no es asi que hay que decir entonces yo repito, "yo voy". Y es asi que hago siempre. Si porque yo no soy brasilera, pero hablo portugués porque me criaron ansi no es. (M)

$\mathrm{M}$ explica também que, quando trabalhava como faxineira numa escola em Rivera, falava em português com todos, inclusive com as professoras. No entanto, revela que, quando a conversa mudava de tom, mudava também de idioma:

4. Quando eu discutia com a maestra eu peleava em castelhano. (M)

No exemplo 5, também retirado da entrevista com $M$, vemos que o gênero discursivo é também determinante da escolha entre o português e o espanhol, ainda quando o contexto é o mesmo, já que $\mathrm{M}$ relata que a língua usada na igreja era o português, mas as funções religiosas se davam em espanhol.

5. Na igreja falava português mas pa lê, cantá, os versiculo, em castellano.

Outra função discursiva realizada através da alternância de códigos é o distanciamento, realizado entre monolíngues com uma mudança de tom ou escolha lexical, mas através de troca de idiomas no discurso bilíngue. Durante a minha estadia em Rivera, em 2006, eu acompanhava uma riverense numa caminhada, quando ela se encontrou com um conhecido, que lhe disse:

\section{C: No te conozco.}

Ao que ela respondeu:

$\mathrm{D}$ : Eu também no te conozco.

Aqui fica clara a tentativa do interlocutor de atuar como um desconhecido ao usar o espanhol. Minha companheira, ao perceber o tom humorístico, aceita a brincadeira ao concordar com a afirmação, em espanhol, de que eram desconhecidos, mas usa o português na primeira parte da frase, ironizando a informação que veio a seguir.

A citação foi um dos recursos discursivos mais comuns nos dados de Zentella; o exemplo 7 reproduz esta estratégia também entre os bilíngues de Rivera:

7. O J. é amoroso, é companheiro. Ao princípio quando ele entrou ai no ano passado em septiembre por ai eu tava de férias e ele entrou. Eu não tava e minha cunhada dizia entró un muchacho allá se ve que es tan asqueroso no le da confianza a nadie - claro, nos primeiros dias ele é ansi tímido não tem confiança com ninguém não.

A alternância de idiomas, comuns em interaçōes espontâneas, é também usada em representaçôes culturais fronteiriças. Chito de Mello, cantor e compositor riverense, tem no seu repertório várias canções que enfatizam representaçôes culturais através da manipulação do repertório linguístico local. Um segmento da música Naum vein que naun tein é reproduzido em 8: 


\section{Não tomo choppe nem ando me gabando}

Como esses frescos de la Sarandí

Tomo cachaça e estoy namorando

Con una barbada de la Manduvi

O narrador da canção de Chito de Mello começa explicando, em português, que não é um "fresco", ou seja, uma pessoa rica, de la Sarandí, a rua central de Rivera, onde socializam membros da classe média, falantes de espanhol. O compositor volta ao português para identificar-se como uma pessoa simples, que "toma cachaça", e conta que está namorando com uma moça de Manduvi, o bairro periférico, falante de português. Enquanto a segunda frase está em português local (atente-se para o uso do empréstimo lexical estoy no lugar do equivalente, em português padrão, estou), há uma mudança para o espanhol na última frase, con una barbada de la Manduvi. Essa alternância enfatiza a identidade fronteiriça através da representação da fala local, além de refletir a distribuição sociogeográfica dos idiomas na cidade de Rivera.

Outras ilustraçôes de competência bilíngue através da produção de alternâncias de códigos foram encontradas em Artigas por Douglas (2004), em Rivera por Waltermire (2006), e em Chuí por Amaral (2008). Embora, muitas vezes, as alternâncias de código não possuam uma função sociodiscursiva clara, essa breve análise demonstra que, em outras circunstâncias, os bilíngues fazem uso da alternância como recurso estilístico. É possível ver, portanto, que, em vez de resultado de uma mistura aleatória entre espanhol e português, a alternância é possível exatamente porque esses indivíduos podem manipular ambos os idiomas. É essencial que essa habilidade discursiva, em vez de excluída e estigmatizada, seja reconhecida e potencializada no âmbito escolar.

\section{2.b Convergência linguística}

Enquanto dificilmente a coexistência das línguas leva à formação de uma terceira variedade (Garret, 2006), inúmeras ocorrências de convergência linguística, além de alternâncias de códigos e empréstimos lexicais ${ }^{1}$, são características de códigos bilíngues, sobretudo durante interação não monitorada entre bilíngues. Woolard (1999) chama a atenção para a perspectiva monolíngue que tem dominado a tradição intelectual oriental e utiliza a noção bakhtiniana que descarta uma visão unitária de língua e enfatiza a justaposição de uma multiplicidade de vozes e forças centrífugas e centrípetas que competem na produção bilíngue (p. 4). Além disso, rechaça a noção binária, enfatizando, em seu lugar, a simultaneidade e o hibridismo que compõem o

l. Ver Carvalho, 2003b e 2007, para uma discussão sobre tipos de empréstimos lexicais em português uruguaio. 
repertório linguístico de comunidades bilíngues. Para a autora, o acesso a ambas as línguas produz a realização simultânea de influências interlinguísticas, alternância de códigos e formas bivalentes. Condizendo com a observação de Woolard, as comunidades bilíngues do norte do Uruguai apresentam, além da escolha binária entre dois códigos e da intercalação desses, uma complexa variedade de influências interlinguísticas que, no caso de idiomas tão parecidos como o português e o espanhol, formam amálgamas e dão vazão a vários casos de convergência linguística, que se diferenciam dos dialetos monolíngues, estabelecem-se no dialeto em contato e passam a fazer parte da gramática de grupo. Um exemplo de uma mudança em português uruguaio causada pelo contato com o espanhol é o uso da partícula "um" como sujeito indeterminado de uma oração, estrutura comum em espanhol. Essa construção é abundante no português uruguaio e está presente, inclusive, em sintagmas preposicionais, como no exemplo 9:

9. Ter fio homi é mais fácil pa um, não é? (Rs.)

$\mathrm{Ou}$ seja, os dialetos fronteiriços contêm tanto formas equivalentes aos dialetos monolíngues, como formas resultantes do contato linguístico. É importante saber distingui-las. Muitas vezes, o que parece distinguir o "português uruguaio" do "português de verdade" é não somente a presença de elementos do espanhol, mas a presença de elementos do português não padrão. Refiro-me à ideia equivocada, por exemplo, de que a vocalização de (lh) é típica da fronteira, o que não leva em conta o fato de ser essa uma variável sociolinguística em português de todo Brasil ${ }^{2}$. Uma breve discussão sobre a variação interna de ambos os dialetos fronteiriços, a seguir, ilustrará melhor essa discussão.

\section{Variação}

Uma importante contribuição da sociolinguística variacionista à teoria linguística é exatamente a ideia de que não há comportamento linguístico categórico, de uma gramática invariável, já que a variação é inerente à linguagem humana. Além disso, a análise variacionista usualmente revela que a variação não é aleatória, mas sistemática. Essa sistematicidade é revelada uma vez que o contexto linguístico e social é incorporado na análise linguística. Assim como nos dialetos monolíngues, os sistemas linguísticos em contato também apresentam variação interna em todos os níveis da gramática. Poplack (1993, p. 252) explica os benefícios da perspectiva variacionista também na análise de

2. A classificação da vocalização como algo peculiar ao português uruguaio está presente também no modelo de análise proposto por Douglas (2004), que sugere um diagrama ternário para ilustrar a relação de três variantes fonológicas, "mulher", pertencente ao "português"; "mujer", pertencente ao "espanhol"; e "muiér", supostamente pertencente ao português uruguaio. 
línguas em contato, já que esta substitui a ideia de pura existência ou gramaticalidade de formas por padrôes de uso de maior ou menor frequência.

Estudos variacionistas das línguas em contato são particularmente importantes para o debate sobre a formação de uma terceira língua, já que substitui a visão monolítica de um dialeto por um leque de variação. No caso do português uruguaio, Lipski (2006) sugere que o português fronteiriço é resultado do contato de duas línguas amalgamadas, ou seja, é uma terceira variedade resultante de certo grau de "disfluência" entre seus falantes. Adiciona o autor que a interpenetrabilidade entre as gramáticas do português e do espanhol possibilita que as línguas compartilhem uma só representação psicolinguística, criando um paradoxo entre a ideia de bilinguismo diglóssico e a ideia de uma terceira língua, falada por monolíngues incapazes de produzir as línguas base. No entanto, ainda que seja plausível a hipótese de que o contato entre línguas cognatas dê vazão a maior grau de convergência linguística, as observações de Behares (2007), Carvalho (2003b, 2007), Elizaincín (2008) e Watermire (2006) indicam que certo grau de separação das línguas nessas comunidades não só é cognitivamente possível, mas socialmente desejável, já que a escolha de línguas está regida por fatores sociais e interacionais. De fato, Meirelles (2009), ao estudar o repertório fonético do português uruguaio falado por bilíngues de Rivera, encontra que este permanece intacto e praticamente igual ao produzido por monolíngues em português residentes em Santana do Livramento, no Brasil, contrariando a ideia da formação de um terceiro idioma, baseada na perda de integridade linguística dos sistemas em contato.

Douglas (2004), baseada em um estudo levado a cabo no departamento fronteiriço de Artigas, argumenta que alguns dos seus participantes usam uma mistura entre o português e o espanhol que deve ser "distinguida das variedades padrôes do espanhol e do português, até que se possa demonstrar que esta variedade foi substituída por bilinguismo entre variedade monolíngue do espanhol e português brasileiro padrão". (2004, p. 115-116) ${ }^{3}$. Ou seja, a autora parece crer que é necessário que os bilíngues controlem ambos os dialetospadrōes das línguas bases. Grosjean (2006) adverte-nos que não podemos determinar a competência linguística dos bilíngues em relação àquelas encontradas entre falantes nativos monolíngues, já que as habilidades linguísticas desses grupos são qualitativamente diferentes, enfatizando que os bilíngues não são dois monolíngues coexistindo num mesmo indivíduo.

3. Minha tradução de "Despite the admixture, in as much as UP bilinguals regard the variety as separate and continue to demostrate na ability to alternate between the languages they command, proficiency in UP should continue to be distinguished from the standard Spanish and Portuguese varieties, until it can be demostrated that is has been supplemented by Spanish monolinguals or Standard Brazilian Portuguese bilingualism." (Douglas, 2004, p. I I 5). 
A ideia do português uruguaio como um dialeto monoestilístico e monolíngue desconsidera o repertório linguístico amplo das comunidades em questão. Uma análise que considera a heterogeneidade como parte integral da economia linguística local revela que nem uma nova língua é formada, nem as línguas são totalmente separadas, fenômeno que seria improvável, em se tratando de coexistência prolongada. Nessas comunidades encontramos, por um lado, a preservação das fronteiras que separam as línguas como um aspecto essencial na organização social que condiciona a escolha de línguas e a alternância de códigos; por outro, uma complexa realidade híbrida, desafiando a noção do bilíngue ideal, que deve ser capaz de patrulhar as fronteiras linguísticas.

Vejamos o seguinte exemplo, retirado de uma entrevista com H., empregada doméstica, também moradora do bairro operário Manduvi, em Rivera: H., na época da entrevista, tinha 42 anos e trabalhava como empregada doméstica no centro da cidade. Havia sido criada em português, na zona rural do departamento de Rivera, pelos pais, ambos trabalhadores agrícolas. Adquiriu espanhol na escola, que cursou até completar o primário, e, segundo relata, usa o espanhol com a família da patroa, com o médico, com os professores dos filhos, em repartições públicas e no comércio, no centro da cidade. Cria seus filhos em português, como é comum no seu bairro, mas observa que eles usam cada vez mais o espanhol. Durante a entrevista, ela me contava sobre seus filhos:

10. Ela sempre se dedicou pa casa, e estudia pa mim podê traba ["] guri de dezoito traba[i]a, traba[i] ai na fábrica, na zona franca que hay ai, viste, tá traba[x]ando hace dies me[s]es - ele traba[i]a aí, num quis sabê de estudo, traba[i]a ai e se defende.

Do começo da narrativa até o marcador de discurso "viste", H. usa português com dois empréstimos lexicais, estudia e hay, formas espanholas que constituem empréstimos praticamente estabelecidos em Rivera (Carvalho, 2007). O marcador de discurso viste, forma bivalente ${ }^{4}$, parece ter atraído uma alternância em direção ao espanhol em tá traba[x]ando hace dies me[s]es, mas H., depois de uma breve pausa, regressa ao português. Vê-se, nesse segmento, que H. faz uso de ambas as variantes de (lh), a padrão [»] e a não padrão [i]; de empréstimos lexicais; formas bivalentes e alternância de códigos, demonstrando acesso a mais de uma língua e a mais de um dialeto. Este segmento revela um discurso pouco monitorado, onde se espera encontrar mais alternância de códigos e uso de empréstimo em comunidades bilíngues em geral (Poplack, 1993, p. 260). H., nessa parte da entrevista, parece estar no que Grosejan (2006) classifica como "bilingual mode", ou um estado psicolinguístico no qual o bilíngue faz

4. Formas bivalentes são elementos que pertencem a duas línguas em contato, às vezes usadas estrategicamente pelos bilíngues (Woolard; Genenovesi, 2007). 
uso simultâneo de ambas as línguas. No entanto, no começo da entrevista, $\mathrm{H}$. parece monitorar mais sua fala, apresentando frequentes autocorreções, em direção ao português padrão, como as encontradas em 11, retiradas aos sete minutos da entrevista:

11. Entonces eu chamo por teléfono, por telefone. Pá falá com os fio dele, os filhos $(\mathrm{M}, \mathrm{B}, 51)$

Nesse segmento em português, $\mathrm{H}$. usa primeiramente a palavra teléfono em espanhol, e logo se corrige, usando o equivalente em português brasileiro telefone. Essa autocorreção em direção ao português brasileiro urbano é seguida pela oscilação entre a forma fio e filhos, onde a variante padrão ["] substitui [j] e o morfema plural $-s$ substitui sua ausência.

Esta breve análise da produção linguística de $\mathrm{H}$. mostra que seu repertório inclui estereótipos linguísticos relacionados ao português uruguaio (empréstimos lexicais, alternância de línguas e variantes rurais, como a vocalização de [»]), ao mesmo tempo que incorpora variantes relacionadas ao português padrão (substituição de empréstimos lexicais por equivalentes em português monolíngue e substituição de variantes rurais por equivalentes urbanos). Portanto, abstrai-se a existência de um contínuo estilístico que una um estilo informal, em que as formas rurais e híbridas abundam, a um extremo formal, monitorado; em que essas formas são evitadas e substituídas por equivalentes do português padrão. Além de fatores contextuais, meus estudos anteriores demonstraram que a variação interna tanto do espanhol como do português fronteiriço está condicionada também por características sociais dos falantes. Os resultados quantitativos mostram uma tendência ao nivelamento dos dialetos locais em direção aos dialetos nacionais, resultante de fortes pressōes normativistas exercidas por interações pessoais com monolíngues e pela exposição aos meios de comunicação. A oscilação entre formas locais e formas padrōes, emprestadas de dialetos falados por monolíngues urbanos, é representada através de um contínuo dialetal (Carvalho, 2003a, 2003b, 2007) e substitui a dicotomia entre um dialeto fronteiriço e as línguas e os dialetos circundantes, ao revelar permeabilidade e fluidez entre grupos e estilos.

A quantificação de duas variantes fonológicas, baseada em dados coletados em Rivera durante entrevistas com 56 bilíngues, ilustra o contínuo dialetal que une o português uruguaio com o português brasileiro. A primeira refere-se à palatalização das dentais oclusivas em contextos onde precedem /i/. A produção oclusiva, relacionada pela comunidade com o português local, tem dado lugar à produção africada, típica do português brasileiro urbano. A segunda variável relaciona-se à pronúncia lateral [»] da variável (lh). Enquanto a vocalização é típica dos dialetos rurais tanto do português uruguaio como do português brasileiro, a pronúncia lateral é a preferida nos meios urbanos e nos estilos mais 
formais. A quantificação de ambas as variáveis ilustram a estratificação sociolinguística do português uruguaio.

Tabela I: Padrões de variação do português uruguaio segundo grupos socioeconômicos

\begin{tabular}{|l|c|c|}
\hline Grupos socioeconômicos & $\begin{array}{c}\text { Palatalização de (di, ti) } \\
\text { (Carvalho, 2004) }\end{array}$ & $\begin{array}{c}\text { Pronúncia lateral de (lh) } \\
\text { (Carvalho, 2003a) }\end{array}$ \\
\hline Baixo & $19 \%(153 / 791)$ & $27 \%(208 / 782)$ \\
\hline Médio-baixo & $24 \%(165 / 693)$ & $55 \%(290 / 526)$ \\
\hline Médio & $52 \%(153 / 791)$ & $76 \%(208 / 782)$ \\
\hline $\begin{array}{l}\text { Total de ocorrências } \\
\text { observadas }\end{array}$ & 2248 & 1737 \\
\hline
\end{tabular}

Os dados apresentados na Tabela 1 são ilustrados na Figura 1.

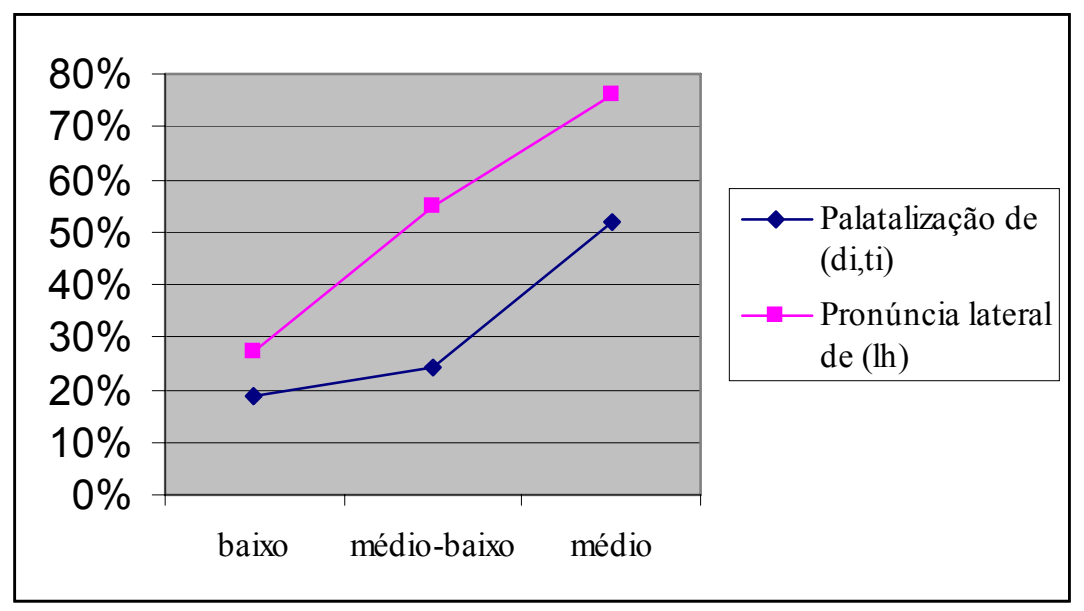

Figura I: Padrões de variação do português uruguaio segundo grupos socioeconômicos

É possível notar que os níveis socioeconômicos baixos mantêm mais frequentemente as variantes conservadoras, que tipificam o português uruguaio tradicional, enquanto os grupos mais altos tendem a substituí-las pelos equivalentes do português brasileiro urbano. Esses padróes de variação assemelhamse aos encontrados no Brasil, no que se refere tanto à palatalização das oclusivas dentais (Pereira de Souza, 2008) como à pronúncia lateral de (lh) (Bortoni- 
Ricardo, 1985; Caruso, 1983; Moura; Ferreira, 2008). A semelhança nos padrões de estratificação sociolinguística de ambos os dialetos, português uruguaio e português brasileiro, deve fortalecer o argumento de que o português uruguaio adota, ou tem como alvo, as variantes urbanas encontradas no Brasil, pois apaga a ideia de isoglossas geográficas, baseada em uma estratificação puramente horizontal e a substitui por uma estratificação vertical.

Os padrões de variação do espanhol falado em Rivera por bilíngues seguem a mesma tendência e estão resumidos na Tabela 2 e ilustrados na Figura 2. A primeira variável quantificada é a aspiração do (s) final de sílaba, inovação linguística na fronteira, trazida de Montevidéu, e, portanto, portadora de certo prestígio. A segunda variável representa a presença de concordância nominal dentro do sintagma.

Tabela 2: Padrões de variação do espanhol fronteiriço segundo grupos socioeconômicos

\begin{tabular}{|l|c|c|}
\hline Grupos socioeconômicos & $\begin{array}{c}\text { Distribuição social de } \\
\text { aspiração de (s) final de } \\
\text { sílaba } \\
\text { (Carvalho, 2006a) }\end{array}$ & $\begin{array}{c}\text { Distribuição social de } \\
\text { concordância nominal } \\
\text { (Carvalho, 2006b) }\end{array}$ \\
\hline Baixo & $12 \%(337 / 2752)$ & $64 \%(541 / 844)$ \\
\hline Médio-baixo & $25 \%(871 / 3415)$ & $73 \%(679 / 926)$ \\
\hline Médio & $41 \%(1355 / 3271)$ & $82 \%(770 / 939)$ \\
\hline $\begin{array}{l}\text { Total de ocorrências } \\
\text { observadas }\end{array}$ & 9438 & 2709 \\
\hline
\end{tabular}

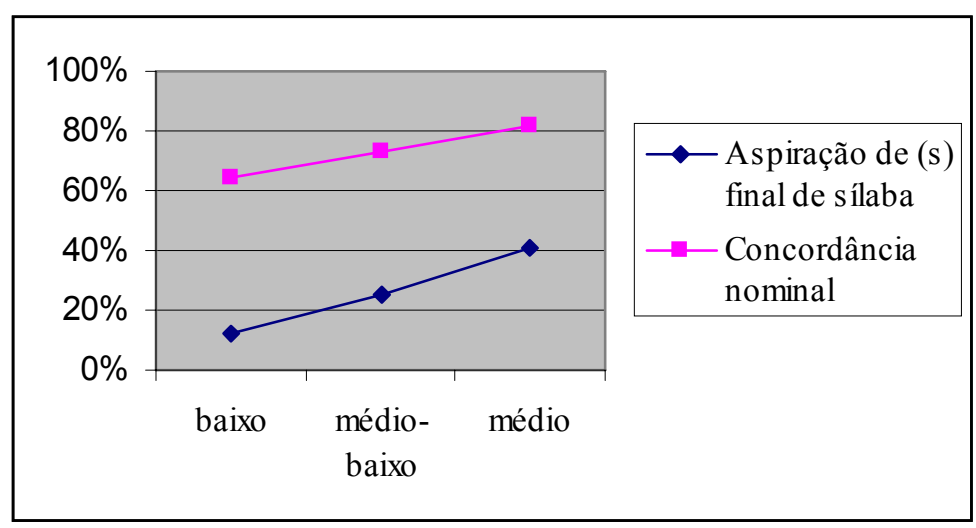

Figura 2: Padrões de variação do espanhol fronteiriço segundo grupos socioeconômicos 
Os padrões de estratificação sociolinguística do espanhol de Rivera também apontam para uma preferência dos grupos sociais mais baixos por formas mais conservadoras, ou seja, desfavorecem a aspiração, pronúncia associada à capital; e a concordância nominal, regra categórica em espanhol padrão, mas variável nos dialetos populares. Os grupos sociais mais altos, por sua vez, adotam a aspiração do (s) final de sílaba e mantêm maior frequência de concordância nominal, seguindo o modelo padrão de Montevidéu.

Os Quadros 1 e 2 resumem os resultados de estudos quantitativos nos moldes variacionais e indicam a tendência do espanhol e do português fronteiriço de incorporar variantes dos dialetos monolíngues circundantes que, na fronteira, passam a coexistir com as variantes locais e são sujeitas à estratificação social. Como resultado, Rivera passa a ser uma zona de transição dialetal onde dialetos rurais e fronteiriços se encontram com dialetos urbanos e monolíngues e incorporam suas variantes, tendo como resultado uma expansão da base vernácula. Formas rurais, alternância de códigos, empréstimos lexicais, convergências gramaticais e formas urbanizadas são usadas estrategicamente para que os falantes articulem seu repertório de identidades sociais e respondam a necessidades interacionais.

\section{Implicações pedagógicas}

O contexto sociolinguístico das comunidades bilíngues do Uruguai, brevemente descrito no presente trabalho, deve ser cuidadosamente considerado no desenvolvimento do currículo de ensino de português. Ao buscar uma pedagogia sensível às diferenças culturais e linguísticas do alunato, o repertório linguístico da comunidade, assim como os diferentes valores sociais e símbolos identitários atribuídos a ele, deve ser considerado no desenvolvimento de objetivos, métodos e materiais didáticos. Nesta sessão, discutirei brevemente as premissas subjacentes ao ensino de língua estrangeira, de língua materna e de língua de herança, a fim de traçar alguns paralelos entre essas premissas com os quais acredito devem ser vinculados os objetivos do ensino de português no Uruguai.

A forte relação entre língua e identidade faz com que o ensino da língua materna se diferencie do ensino das outras matérias. Como nos alerta Fought (2006), o ensino do dialeto padrão não é nada similar ao ensino de matemática, por exemplo. As crianças não chegam à escola com um sistema matemático que faça parte integral de sua identidade e não aplicam princípios matemáticos específicos que expressem relaçôes entre eles e sua família e amigos. Exatamente porque a língua é parte essencial da identidade, o ensino de língua materna é diferente do ensino de qualquer outra matéria. 
É precisamente devido aos valores sociais atribuídos às línguas e aos dialetos locais nas comunidades bilíngues do Uruguai que o ensino do português difere também do ensino de português como língua estrangeira. Primeiramente, há nessas comunidades um contato intenso entre o português e o espanhol na sociedade em geral e no sistema linguístico-cognitivo de cada falante, diferentemente do que ocorre no ensino de língua estrangeira, em que há a aquisição gradual do português através da instrução formal. Portanto, já é possível ver uma diferença fundamental: enquanto o português uruguaio é um dialeto comunitário, o português que se desenvolve na sala de aula de língua estrangeira consiste em interlínguas individuais.

Outra diferença importante entre o português uruguaio como dialeto coletivo e o português desenvolvido no contexto de ensino de língua estrangeira é o fato de que, nas comunidades do norte do Uruguai, o bilinguismo é circunstancial e não voluntário, como é o caso do ensino de línguas estrangeiras, em que os indivíduos tomam a iniciativa de aprender outra língua. O que leva o/a estudante a querer aprender outra língua em contextos de ensino de língua estrangeira é geralmente o capital simbólico que a nova língua oferece, o que difere da situação do ensino do português uruguaio, uma vez que este não tem valor instrumental, mas um forte valor integrativo.

Em termos de consequências linguísticas resultantes do contato entre o espanhol e o português em caso de bilinguismo social e contextos de aquisição, ambas as situaçōes favorecem vários níveis de congruência. Há evidências de que os estudantes de português que têm o espanhol como sua língua nativa constroem a gramática do português com base no conhecimento que têm em espanhol, fato comum na aquisição de línguas parecidas. Esse alto grau de transferência resulta num processo de aquisição mais rápido, graças à grande possibilidade de transferência positiva das estruturas e dos vocabulários congruentes (Simões; Carvalho; Wiedemann, 2004). As congruências sintáticas e morfológicas que se encontram no português uruguaio são notadas também esporadicamente na gramática do português que os falantes nativos de espanhol constroem aos poucos na sua interlíngua. A diferença está em que, enquanto o indivíduo, durante o processo de aquisição de línguas, produz vários tipos de construçôes que resultam de transferência da L1 (primeira língua), essas construções não chegam a cristalizar-se em padrões de uso comunitário, como é o caso do português uruguaio, no qual, por exemplo, a construção com UM como sujeito indeterminado já faz parte da gramática de grupo, tornou-se uma variante regional e adquiriu valor social, diferentemente do que acontece com interlínguas individuais nos contextos de aquisição.

Cabe frisar que os padrôes de alternâncias de código também apresentam diferenças. Enquanto os alunos de português como língua estrangeira, espora- 
dicamente, inserem palavras ou grupos de palavras em espanhol na sua produção em português com fim compensatório, os bilíngues, muitas vezes, usam a alternância de códigos para atingir objetivos pragmáticos conversacionais, como vimos nos exemplos discutidos neste trabalho. É possível ver, portanto, através dos resultados da sociolinguística, que há diferenças fundamentais entre os contextos de bilinguismo e o contexto de aquisição de línguas estrangeiras.

A relevância da pesquisa sociolinguística no ensino tem sido explorada desde a década de sessenta do século passado, quando Labov (1969) explicou, em seu estudo sobre a lógica do inglês não padrão, a importância de entender os dialetos sociais. Desde então, a sociolinguística tem contribuído com questões pedagógicas tanto no ensino de língua materna, em sociedades monolíngues, como no ensino de língua de herança, em comunidades bilíngues, ambos os contextos relevantes para o ensino de português nas comunidades bilíngues do Uruguai.

No Brasil, a vasta produção sociolinguística tem contribuído com importantes parâmetros pedagógicos para o ensino de português como língua materna, visto que a diferença entre o português padrão e o português falado pelos estudantes, sobretudo da rede pública, é abismal (Bagno, 2003; BortoniRicardo, 2004, 2005; Mattos Silva, 1994, entre outros). Nessa esfera, a contribuição da sociolinguística dá-se através da difusão de esclarecimentos sobre a natureza variável dos idiomas e o sistema de valorização social atribuído aos socioletos e trata de combater os mitos de pureza e correção linguística prevalecentes entre professores, administradores e membros da sociedade em geral. No contexto educacional, esses mitos afetam negativamente a socialização e a aprendizagem dos alunos falantes de socioletos estigmatizados, problematizando o rendimento acadêmico e agravando o problema da evasão escolar.

Como no Brasil, nas comunidades bilíngues do Uruguai, as variantes que se desviam do português ou do espanhol padrão são consideradas indesejáveis, independentemente do contexto em que ocorram. O português uruguaio, além de manter a maioria dos desvios da norma-padrão típicos do português rural, possui o agravante de incorporar elementos do espanhol. Do ponto de vista valorativo, ambas as características são vistas como desvios do português brasileiro urbano e, portanto, são estigmatizadas. Além disso, as comunidades bilíngues uruguaias compartilham com os estudantes da rede pública brasileira o acesso limitado à norma-padrão. Portanto, é condição sine qua non que uma pedagogia sensível à diversidade linguística dos alunos combata o estigma linguístico e preserve os saberes sociolinguísticos e os valores culturais que o aluno já possui. Bortoni-Ricardo sugere uma "pedagogia culturalmente sensível", cujo objetivo é "criar em sala de aula ambientes de aprendizagem onde se desenvolvam padrões de participação social, modos de falar e rotinas comunicativas presentes na cultura dos alunos" (2005, p. 130). Ao mesmo tempo que 
se valorizam os modos de fala nativos dos alunos, o objetivo da escola é "facilitar a incorporação ao repertório linguístico dos alunos de recursos comunicativos que lhes permitam empregar com segurança os estilos monitorados da língua, que exigem mais atenção e maior grau de planejamento." (Bortoni-Ricardo, 2005, p. 131). Assim, faz-se necessário, primeiramente, que a escola conheça o repertório linguístico dos alunos, sem equivocações e livre de preconceitos linguísticos.

O português tem sido preservado como língua minoritária no Uruguai através das geraçôes, sem apoio institucional, característica das línguas de herança em comunidades bilíngues. Um falante de uma língua herdada é definido por Valdes (1995, p. 38) como "aquele que é criado numa casa onde se fala ou pelo menos se compreende uma língua que não é a língua oficial de sua comunidade, e que é, até um certo ponto, bilíngue na língua de casa e na língua oficial da comunidade". Em oposição ao ensino de línguas estrangeiras, no caso de ensino de línguas de herança, o papel da identidade permeia todo o campo, devido precisamente às relações intrínsecas entre identidade e língua. Portanto, o caráter sociolinguístico dessa população estudantil determina métodos e objetivos diferentes daqueles aos quais estamos acostumados no campo de ensino de língua estrangeira, sobretudo no que se refere à noção de "erro". Faz-se necessário, sobretudo, evitar a propagação de preconceitos linguísticos, ou seja, julgamentos normativistas centrados no que é certo ou errado na língua, e a consequente avaliação social que atribui prestígio ou estigma às diferentes falas, mas que, na realidade, atingem diretamente os falantes.

Nos últimos anos, tem sido recomendado que o ensino de língua materna em comunidades monolíngues ou de línguas de herança em comunidades bilíngues tenha como objetivo a educação bidialetal. Assim, é proposto que se reconheça o valor instrumental da norma culta e o valor afetivo dos dialetos locais e bilíngues e que se inclua, além disso, uma discussão sobre a arbitrariedade do preconceito linguístico e da valorização da norma culta. Martínez (2003) sugere que não somente se inclua uma "consciência dialetal" (ou seja, sobre os diferentes dialetos), mas uma consciência dialetal crítica. Sua preocupação é que, ao dizer aos estudantes que devem adquirir o dialeto de prestígio para usá-lo em situaçóes que o exijam, deixamos de discutir por que razão seu dialeto nativo não é apropriado para essas situações formais. Martínez (2003, p. 5) propõe, então, que se leve à sala de aula uma discussão sobre a relação entre língua, poder e grupos sociais para que a desigualdade de valores sociais atribuídos aos dialetos não se reforce na sala de aula, mas seja discutida, compreendida e questionada.

Para o desenvolvimento de consciência dialetal, têm-se usado métodos que contrastem a variedade local e a variedade-padrão. Essa perspectiva utiliza a 
competência linguística das crianças, trazendo seu dialeto à sala de aula e, portanto, concedendo-lhe valor social através do reconhecimento - uma orientação mais positiva que os modelos que almejam a substituição do dialeto nativo pelo dialeto padrão. Como ressaltam Rickford e Rickford (2007), na proposta do ensino do inglês para falantes de dialetos minoritários, através da análise do seu próprio sistema linguístico e de comparaçôes com os dialetos majoritários, espera-se que os professores e os estudantes se tornem variacionistas, ou seja, aprendam a compreender a variação e a buscar padrôes de uso e frequência que substituam a ideia de erro e de mistura de línguas. No caso do português uruguaio, o discernimento entre variantes do português rural, empréstimos lexicais, alternâncias de código e convergências interlinguísticas seria de grande valia, na medida em que substituiria a ideia de uma mistura indiscriminada, um "portunhol", por um maior entendimento das influências que determinam os padrōes de variação em português uruguaio. Como material para esse tipo de análise, seria conveniente que se usassem textos autênticos. Por exemplo, as receitas culinárias organizadas por Behares, Diaz e Holzmann (2004), as letras de músicas de Chito de Mello e gravaçôes de histórias contadas pelos mais velhos em português uruguaio seriam ricas fontes de material para análise na sala de aula. O uso desse material revelaria a ecologia linguística local, aguçaria a consciência metalinguística dos estudantes e valorizaria o repertório multidialetal e bilíngue da fronteira; e assim, e por fim, o mito do monolíngue em portunhol seria substituído. Dessa maneira, seria dada a devida atenção à diversidade linguística no processo educacional, diversidade essa aqui revelada tanto através de análises quantitativas de variáveis intralinguísticas como de breves análises interacionais de fenômenos interlinguísticos.

\section{Referências bibliográficas}

AMARAL, Tatiana R. La producción de cambios de código en la frontera Chuí-Chuy y su papel en la construcción de la identidad fronteriza. In: ESPIGA, J.; ELIZAINCÍN, A. (Org.). Españoly português: um (velho) Novo Mundo de fronteiras e contatos. Pelotas: Educat, 2008. p. 209-234.

BAGNO, Marco. Norma culta -língua e poder na sociedade brasileira. São Paulo: Parábola, 2003.

BEHARES, Luis E. Diglosia en la sociedad escolar de la frontera uruguaya con Brasil. Matriz social del bilingüismo. Cuadernos de Estudios Lingüísticos, n. 6, p. 228-234, 1984.

BEHARES, Luis E. Português del Uruguay y educación fronteriza. In: BROVETTO, Claudia; BRIAN, Nicolás; GEYMONAT, Javier (Ed.). Portugués del Uruguay y educación bilingüe. Montevideo: Administración Nacional de Educación Pública, 2007. p. 99-171.

BEHARES, Luis E.; DÍAZ, Carlos E.; HOLZMANN, Gerardo. Na frontera nós fizemo assim. Lengua y cocina en el Uruguay fronterizo. Montevideo: Librería de la Facultad de Humanidades y Ciencias de la Educación, 2004. 
BORTONI-RICARDO, Maria Stella. The urbanization of rural dialects. Cambridge: Cambridge University Press, 1985.

BORTONI-RICARDO, Maria Stella. Educação em língua materna. A sociolingüistica em sala de aula. São Paulo: Parábola, 2004.

BORTONI-RICARDO, Maria Stella. Nós cheguemos na escola, e agora? Sociolingüística e educação. São Paulo: Parábola, 2005.

CARUSO, Pedro. A iotização do /lh/ segundo o Atlas prévio dos falares baianos. Alfa, n. 27, p. 47-52, 1983.

CARVALHO, Ana Maria. The sociolinguistic distribution of (lh) in Uruguayan Portuguese: a case of dialectal diffusion. In: MONTRUL, Silvina; ORDONEZ, Francisco (Ed.). Linguistic theory and language development in Hispanic languages. Papers from the $5^{\text {th }}$ Hispanic Linguistics Symposium and the $4^{\text {th }}$ Conference on the Acquisition of Spanish and Portuguese. Somerville: Cascadilla Press, 2003a. p. 30-43.

CARVALHO, Ana Maria. Rumo a uma definição do português uruguaio. Revista Internacional de Lingüística Iberoamericana, n. 2, p. 135-159, 2003 b.

CARVALHO, Ana Maria. "I speak like the guys on TV": palatalization and the urbanization of Uruguayan Portuguese. Language Variation and Change, v. 16, n. 2, p. 127-141, 2004.

CARVALHO, Ana Maria. Nominal number marking in a variety of Spanish in contact with Portuguese. In: FACE, Timothy; KLEE, Carol (Ed.). Selected Proceedings of the 8th Hispanic Linguistics Symposium. Somerville, MA: Cascadilla Proceedings Project, 2006a. p. 154-166.

CARVALHO, Ana Maria. Spanish (s) aspiration as a prestigious marker on the UruguayanBrazilian border. Spanish in Context, v. 3, n. 1, p. 85-114, 2006 b.

CARVALHO, Ana Maria. Políticas lingüísticas do século passado nos dias de hoje. O dilema da educação bilíngüe no Uruguai. Language Problems and Language Planning, v. 30, n. 2, p. 149171, 2006c.

CARVALHO, Ana Maria. Diagnóstico sociolingüístico de comunidades escolares fronterizas en el norte de Uruguay. In: BROVETTO, Claudia; BRIAN, Nicolás; GEYMONAT, Javier (Ed.). Montevideo: Administración Nacional de Educación Pública. República Oriental del Uruguay, 2007. p. 44-96.

CARVALHO, Ana Maria. "Português não, portuñol”: ideologias e atitudes lingüísticas sobre o português uruguaio. In: CONGRESSO INTERNACIONAL DA ALFAL, 15., 20 de agosto de 2008, Montevidéu, Uruguai.

ELIZAINCÍN, Adolfo. El bilingüismo de la frontera uruguayo-brasileña. Letras de Hoje, n. 20, p. 65-75, 1975.

ELIZAINCÍN, Adolfo. Bilingüismo y problemas educativos en la zona fronteriza UruguayoBrasileña. Lingüistica y Filología de América Latina. Lima: Universidad de San Marcos, p. 301310, 1978.

ELIZAINCÍN, Adolfo. Dialectos en contacto. Español y Portugués en España y América. Montevidéu: Arca, 1992. 
ELIZAINCÍN, Adolfo. Oito considerações sobre o contato linguístico. In: ESPIGA, J; ELIZAINCÍN, A. (Org.). Españoly português: um (velho) novo mundo de fronteiras e contatos. Pelotas: Educat, 2008. p. 405-424.

DOUGLAS, Kendra L. 2004. Uruguayan Portuguese in Artigas. Tri-dimensionality of transitional local varieties in contact with Spanish and Portuguese standards, Tese (Doutorado) — University of Wisconsin, Madison, 2004.

FERGUSON, Charles. Diglossia. Word, n. 15, p. 325-340, 1959.

FISHMAN, Joshua. Language and nationalism. Rowley: Newbury, 1972.

FOUGHT, Carmen. Language and ethnicity. Cambridge: Cambride University Press, 2006.

GARRET, Paul. Language contact and contact languages. In: DURANTI, A. (Ed.). A companion to linguistic Anthropology. Malden, MA/ Oxford, UK: Blackwell Publishing, 2006.

GROSJEAN, François. Studying bilinguals: methodological and conceptual issues. In: BHATIA, T. K.; RITCHIE, W. C. (Ed.). The handbook of bilingualism. Malden, MA, USA; Oxford, UK: Blackwell, 2006. p. 32-63.

LABOV, William. The study of nonstandard English. Washington, DC: National Council of Teachers of English, 1969.

LIPSKI, John. Too close for comfort? The genesis of portuñol/portunhol. In: FACE, Timothy; KLEE, Carol (Ed.) Selected Proceedings of the 8th Hispanic Linguistics Symposium. Somerville: Cascadilla Proceeding Project 2006. p. 1-22.

MARTÍNEZ, Glenn. Classroom based dialect awareness in heritage language instruction: a critical applied linguistic approach. Heritage Language Journal, v. 1, n. 1. 2003.

MATTOS E SILVA, Rosa. Tradição gramatical e gramática tradicional. São Paulo: Contexto, 1994.

MEIRELLES, Virginia Andrea Garrido. O português da fronteira Brasil-Uruguai. In: CARVALHO, Ana Maria (Ed.) Português em contato. Madrid: Iberoamericana; Frankfurt: Verveut, 2009. p. 257-275.

MOURA, Cleide Queiroz de Paula; FERREIRA, Janaína Soares Silva Reis. Metaplasmos no falar urbano monte-belense: um estudo sobre apócope e vocalização. Ícone - Revista de Letras, São Luís de Montes Belos, n. 2, p. 196-210, 2008.

PEREIRA DE SOUZA, Milena. O que podi ou podji esta língua: as consoantes oclusivas /d, t/ diante da vogal alta /i/ em dados do projeto Atlas Lingüístico do Brasil. In: CONGRESSO DA ALFAL, agosto de 2008, Montevidéu.

POPLACK, Shana. Sometimes I'll start a sentence in Spanish y termino en español. Toward a typology of code-switching. Linguistics, v. 18, n. 7- 8, p. 581-618, 1980.

POPLACK, Shana. Variation theory and code-switching. In: PRESTON, Dennis R. (Ed.) American dialect research. Amsterdam: John Benjamins, 1993.

RICKFORD, Angela; RICKFORD, John. Variation, versality, and contrastive analysis in the classroom. In: BAYLEY, R; LUCAS, C (Ed.). Sociolinguistic variation. Theories, methods, and applications. Cambridge: Cambridge UP, 2007. p. 254-275. 
SILVA-CORVALÁN, Carmen. Language contact and change. Spanish in Los Angeles. Oxford: Oxford UP, 1996.

SIMÕES, A; CARVALHO, A. M.; WIEDEMANN, L. (Ed.). Português para falantes de espanholPortuguese for Spanish speakers. Campinas: Pontes, 2004.

VALDES, Guadalupe. The teaching of minority languages as "foreign" languages: Pedagogical and theoretical challenges. Modern Languages Journal, v. 79, n. 3, p. 299-328, 1995.

WALTERMIRE, Mark. Social and linguistic correlates of Spanish and Portuguese bilingualism on the Uruguayan-Brazilian border. Tese (Doutorado) — University of New Mexico, 2006.

WOOLARD, Kathryn A. Simultaneity and bivalency as strategies in bilingualism. Journal of Linguistic Anthropology, v. 8, n. 1, p. 3-29, 1999.

WOOLARD, Kathryn; GENOVESE, E. Nicholas. Strategic bivalency in Latin and Spanish in early modern Spain. Language in society, n. 36, p. 487-509, 2007.

ZENTELLA, Ana Celia. Growing up bilingual. Oxford: Blackwell, 1997.

Recebido em 04 de fevereiro de 2010 e aprovado em 07 de julho de 2010. 